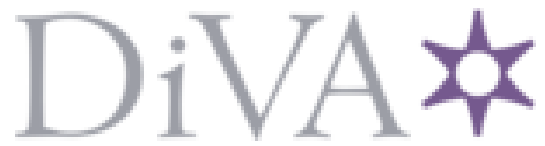

http://www.diva-portal.org

\title{
Postprint
}

This is the accepted version of a paper published in Journal of New Music Research. This paper has been peer-reviewed but does not include the final publisher proof-corrections or journal pagination.

Citation for the original published paper (version of record):

Hansen, K F. (2002)

The basics of scratching

Journal of New Music Research, 31(4): 357-365

https://doi.org/10.1076/jnmr.31.4.357.14171

Access to the published version may require subscription.

N.B. When citing this work, cite the original published paper.

Permanent link to this version:

http://urn.kb.se/resolve?urn=urn:nbn:se:kth:diva-11921 


\section{The basics of scratching}

Kjetil Falkenberg Hansen

Royal Institute of Technology, Speech, Music and Hearing, Stockholm, Sweden.

Email: hansen@speech.kth.se

tel +4687907857

fax +4687907854 


\begin{abstract}
This article deals with the popular and rarely studied art form of manipulating a vinyl record by rhythmically dragging and pushing it, commonly labelled "scratching". With sufficient practice, a Disc Jockey (DJ) can have great control over the sound produced and treat the turntable as an expressive musical instrument. Even though a digital-based model of scratching might seem preferable to the vulnerable vinyl record, and such models are being manufactured today, the acoustical behaviour of the scratch has not been formally studied until now. To gain information of this behaviour, a DJ was asked to perform some typical scratching patterns. These common playing techniques and the corresponding sounds have been analysed. Since the focus of the article is on the basics of how the instrument works, an overview on standardized equipment and alternative equipment is also given.
\end{abstract}




\section{Introduction}

To scratch means to drag a vinyl record forwards and backwards against the needle on an ordinary turntable along the grooves, not across, though it might sound like it. This way of producing sounds has during the last two decades made the turntable become a popular instrument for both solo and ensemble playing in different musical styles, still mostly in hiphop where Disk Jockeys (DJs) first started to scratch. However, all musical forms seem to keenly adopt the turntables into its instrumental scenery. Composers in traditions like rock, metal, pop, disco, jazz, experimental music, film music, contemporary music and numerous others have been experimenting with DJs the past years. Experimental DJs and most hip-hop DJs now frequently call themselves "turntablists", and the music style of scratching and extensive cut-and-paste mixing is called "turntablism". These terms, derived from "turntable", are now generally accepted. It is also generally accepted that a turntablist is a musician and that the turntable is to be considered an instrument.

In the early eighties, scratching DJs and the entire hip-hop community got the attention of the record-buying generation, gradually spreading their sounds to the rest of the musical world. DJs appeared on recordings by artists as diverse as John Zorn (1982), Herbie Hancock (1983), Mr Bungle (1991), Portishead (1994), David Byrne (1997) and Tom Waits (1999). The first experiments with use of phonograph to create music started about 1915 and were carried on through the next three decades by Stephan Wolpe, Paul Hindemith, Ernest Toch, Percy Grainger, Edgar Varèse, Darius Milhaud and Laszlo Moholy-Nagy (Cutler, 1994). None of these composers were turntable artists, nor did they write compositions for turntable that still exist (although some compositions may be reproduced by memory). John Cage (1939) and Pierre Schaeffer (1948) composed what are considered the first pieces for turntables, but they are recognized mainly for their approach to sounds, not to the turntable. Pierre Schaeffer's concept of musique concrete is as much a result from tape-manipulation as vinylmanipulation, and his practices would probably have been commenced even without the phonograph technology (Griffiths, 1995; Khazam, 1997).

Instrumentalists must learn to incorporate a variety of techniques and methods for tone manipulation in their playing, and DJs have established a fundamental ground with an almost compulsory assortment of techniques. All new ways of playing and scratching are persistently explained and debated on, especially on Internet discussion forums on sites devoted to turntablism (e.g. www.scratchdj.com). Some of the accepted techniques will be described and analysed in the following. Numerous techniques more or less resemble, and often originate, from those described, but will not be included in this study. Many ways to scratch do not fit into the general scheme, and are not widely used. They are, however, all explained on turntablism Internet sites as soon as they surface. This overview will not deal with the more unconventional scratches.

Turntablism includes both scratching, using one turntable, and beatjuggling, using two turntables. Scratching is a typical solo-playing style, comparable to that of electric guitar. The musician expresses in intricate rhythmical patterns and in tonal structures. Beatjuggling sometimes has a rhythmical backing function to hip-hop rapping, but is also often played in expressive solo-acts. A history of turntablism and overview of the practice of using turntables as instruments has been reported in a previous paper (Hansen, 2000). 
Research in this field has lately led to improved "scratchable" CD-players and software like Flashwave-based applications and turntable simulators. Still they seem insufficient as replacement for the present equipment as the turntablism-society unfailingly sticks to vinyl. The apparent unwillingness to make use of these innovations has a counterside in a desire to have easier access to sounds and to be spared the frustration of skipping needles and expenses of replacing wrecked records. Some actual examples of such hardware and software will later be discussed shortly in the paragraph "Scratch-equipment based on digital technology".

\section{Equipment}

Any turntable might be used for scratching, but the standard is a direct-driven machine with the platter mounted on the motor. Scratching also utilizes an audio mixer with a volume control that mostly is used for controlling the onsets and offsets of tones. Therefore, the turntable as a musical instrument includes the turntable with pick-up, slip-mat, mixer and a vinyl record. Relatively few manufacturers have succeeded to enter the market with purposeful equipment, compared to the massive popularity and prospective of good sales. Turntablists seem to be sceptical to adapt to radical innovations, especially those that oversimplify and trivialize playing. One example is the production of a mixer that allows for some of the hardest techniques to be played with ease. This particular mixer, Vestax Samurai (Vestax, 2002), never got much positive attention from the professionals, even though it could aspire to development of new techniques. Why this is so and which consequences this inflict on the evolution of the scene is an extensive discussion. In brief, displacement technology could be considered to cheapen the musician's skill, and this explains the hesitation to switch to such technology (Godlovitch, 1998).

A list grasping over most of the major manufacturers includes Technics and Vestax, that make DJ turntables, Vestax, Numark, Ecler and Rane that all make specially designed mixers, and Shure, Stanton and Ortofon that make cartridges (pick-ups) for scratching. (All manufacturers of hardware and software mentioned in this article are listed by brand name in the reference section with URLs.) Low budget equipment from less-known manufacturers fails to convince users. The standard line-up for many turntablists is two Technics SL-1200 Mk2 turntables with Shure M44-7 pick-ups, and a scratch mixer without unnecessary controllers (in the following, "Technics" refers to the Technics SL1200 Mk2 or its black counterpart SL1210 Mk2). Normally this equipment is organized with one turntable placed on either side of the mixer, and to avoid uncontrolled contact with the sensitive tone-arm the turntables are even flipped $90^{\circ}$ with the tone-arms away from the body.

The quartz direct-driven Technics has advantages to the belt-driven turntables in terms of pick-up speed and motor strength (the starting torque of a Technics is $1.5 \mathrm{~kg} / \mathrm{cm}$ ). When pushing the start-button, a mere third of a revolution $(0.7 \mathrm{~s})$ is needed to reach full speed at 33 $1 / 3 \mathrm{rpm}$ (revolutions per minute), and stopping the record goes even faster (Smith, 1999).

With a felt slipmat lying between the platter and the record, moving the record in both directions with the motor on and the platter still going is fairly easy. In rougher moves and 
when maintaining a heavier touch, the platter might follow the record movement, but because of the pick-up speed, that is not a problem.

The pick-up mechanism is specially designed for scratching to prevent the diamond stylus tip from skipping from one groove to another, and even the stylus tip is designed to make scratching easier. "Needle" is the popular term for both the stylus tip and the bar or tube that holds it, called the cantilever. Normal high fidelity styli are often elliptical at the end to follow the groove better, while scratch styli are spherical and made stronger as the force on the needle get so high that both the reels and the needle are in hazard of being damaged. An M44-7 can handle three times the tracking force (the force holding the needle in the groove) of the hi-fi cartridge Shure V15 VxMR - up to $3.0 \mathrm{~g}$ (grams) on the M44-7 compared to 1.00 $\mathrm{g}$ on the V15. Output voltage from the scratch cartridges is $3-4$ times higher $(9.5 \mathrm{mV})$ than the hi-fi cartridge. The hi-fi cartridge has better frequency response, from 10 to $25000 \mathrm{~Hz}$, compared to M44-7's 20 to $17000 \mathrm{~Hz}$. On scratch cartridges the cantilever holding the stylus has high mass and stiffness, and the high frequency range is much affected and poorly reproduced. M44-7 has twice the cantilever diameter compared to V15.

\section{PLEASE INSERT FIGURE 01 HERE!}

The mixer, see Fig. 1(a), has other features than just amplifying, the most important ones are the volume controls and crossfader. Mixers were originally designed for switching smoothly between two turntable decks when doing beat mixing, making one section of a record last for as long as wanted by cross mixing between two identical records. All mixers have for both stereo channels at least a volume fader and tone controls (bass, mid and treble ranges). The central control is the crossfader, positioned at the front end of the mixer. Figure 1 (b) shows crossfader and volume faders.

The crossfader glides seamlessly from letting in sound from channel 1 (left turntable), through mixing signals from channel 1 and channel 2, to channel 2 (right turntable) only. Whether a left-positioned crossfader shall let in sound from left or right turntable is now adjustable with a special hamster-switch. Several varieties in how the crossfader operates are fabricated, one of the newest developments being Rane's non-contact magnetic faders (Rane, 2001). "Fader" might, however, be a misguiding term as the fading curve on the crossfader normally is adjusted to be very steep, making it act as an on-off switch.

Any vinyl record might be used for scratching, but during the last ten years sounds with certain qualities have dominated. Only fragments of original recordings are being manipulated, often shorter than one second. Isolated musical incidents like drumbeats, guitar chords, orchestra hits or words represent the majority of sounds used. Especially the sung, spoken or shouted words from little known recordings, commercials and films are preferred. To simplify playing, and for obvious economical reasons, a number of popular sounds are compiled on one record pressed for DJ use, commonly called a battle record (copyrighting is understandably an abiding but disconcerting question). The sound samples come without long gaps in one track. Longer sentences are often scratched one word or syllable at the time. Short sounds can be given different onsets and offsets depending on the technique used by the DJ. Results of different techniques applied to these sounds will be analysed in the following. 


\section{Material}

DJ $1210 \mathrm{Jazz}$, an experienced DJ, was instructed to perform some typical techniques, both independently and in a natural musical demonstration, and he also included more unusual examples. He was restricted to one frequently used sound, the breathy-sounding $a h h h$-sample (a chorused voice sings ahhh with a falling glissando in the end) from Fab Five Freddie (1982).

The sound material was recorded directly to DAT at $48 \mathrm{kHz}$. All scratching was performed by DJ $1210 \mathrm{Jazz}$ on a Technics SL-1210 Mk2 turntable equipped with a Shure M44-7 pick-up, and a Technics SHDJ1200 mixer. The recordings lasted for about 30 minutes, out of which long sections (several seconds) of continuous playing of a single technique were extracted. About 20 different techniques were recorded in this session.

Recordings were analysed using Wavesurfer (Sjölander \& Beskow) and Soundswell Signal Workstation software (Hitech Development; see references).

\section{Techniques}

\subsection{Basic movements}

Basic DJ hand movements are naturally distinguished in two separate entities; record movement and mixer (crossfader) movement. Most scratching techniques are derivatives from fast but rather simple movements. Record-control and mixer-control depend strongly on one another, analogous to right and left hand in guitar playing. Both hands can operate both devices, and most players switch hands effortlessly, both for playing purpose and for visual showing-off purpose. Even techniques where both hands go to the same device are being performed. A general rule has been to have the strong hand on the vinyl, but with a more intricate use of crossfader, learners now tend to use their strong hand on the mixer instead. The volume controls (foremost the crossfader) are handled with fingertips and are often bounced swiftly between thumb and index. The record is pushed back and forth in every imaginable manner. Travelling distance for the vinyl varies from less than $10^{\circ}$ to more than $90^{\circ}$ in each direction.

Onsets and offsets are conditioned on the position of the sample when starting a scratch, the use of crossfader, and the speed of the movement. Three fundamentally different 
onsets are possible to achieve. First, a scratch movement can start before the sound sample, and the acceleration then completes before the sound cut in. The crossfader will have no effect. In the second kind of onset, the scratch movement starts within the sound sample without use of crossfader; the record will speed up from stand still and produce a very fast glissando from $20 \mathrm{~Hz}$ to desirable pitch, often above $1 \mathrm{kHz}$. A third onset category occurs when the crossfader cut in sound from within the sample, creating an insignificant crescendoeffect, as if it was switched on. Any sound can be deprived of its original attack by cutting away the start with the crossfader.

\section{PLEASE INSERT FIGURE 02 HERE!}

Figure 2 shows a sector of a record with a sampled sound on it. The y-axis represents position in the sample. There are eight different forms of a forward-backward motion, marked (a)-(h). All movement types are permutations of starting, turning and stopping either within or without the sampled sound. Movement types (a)-(b) and (e)-(f) start before the sound, and movements (c)-(d) and (g)-(h) start within the sound. Movements (a), (c), (e) and (g) have the change of direction outside the borders of the sound, while (b), (d), (f) and (h) change direction within the sound. Movements (a)-(d) end outside the sound border, while (e)-(h) end before the sound has finished.

Besides the starting, turning and stopping points, several other factors have bearing on the output sound of a simple forward and backward movement: Direction, or whether to start with a push or a pull, is an effective variable. The speed changes the pitch, and can be fast or slow, steady or shifting. In addition to controlling sounds with the record-moving hand, the crossfader gives the DJ the option to produce alternative onsets and offsets. What kind of sound sample all variables are executed on greatly affects the result.

\section{PLEASE INSERT FIGURE 03 HERE!}

Figure 3(a) and 3(b) show some interesting features of the sounds. They are both illustrations of a very simple scratch (this specific one will be explained as baby-scratching) similar to type (b) in Fig. 2. The scratch is approximately $0.4 \mathrm{~s}$ long and can in traditional musical notation resemble two sixteenth notes at about $75 \mathrm{bpm}$ (beats per minute). The original sound ( $a h h h)$ has a noise band with a broad maximum, inducing the perception of a pitch. Arguably the first sixteenth has a broad maximum around $1200 \mathrm{~Hz}$ and the second sixteenth around $2400 \mathrm{~Hz}$, or an octave higher, but it is hard to establish a definite tonal phrase because of the glissando effects that can be observed in the spectrogram in Fig. 3(b). The first sixteenth starts abruptly when the sound cuts in, evident on the amplitude level figure, while the second sixteenth has a smoother attack with increase of both frequency and amplitude. 
Ending of tones can equally be divided into three categories, with the quick slowing down to a halt perhaps being the most interesting one. During a scratch performance, a big portion of the onsets and offsets are just the record changing direction within the boundaries of a sound sample. Figure 4 shows a combination of movement type (e) followed by type (c), both from Fig. 2. It means that the $0.8 \mathrm{~s}$ long scratch is built up by four sixteenth notes at 75 $\mathrm{bpm}$. The first sixteenth has an abrupt attack, while the second and fourth sixteenths have a more smooth attack. The third sixteenth has a faster attack than the second and the fourth, but the sound is still achieved in the same way. The explanation to these differences lies in the speed of the turn of record direction. In the example in Fig. 3, the turn when going from forward to backward movement is quicker than the turn when going from backward to forward again - the initial move from the body is faster than the initial move towards the body. All the endings except from the last one are results of slowing down the record to change the direction, producing a fast drop in frequency.

The pitch we perceive from the broad maximum of the noise band is determined by the original recording and by the speed by which it is played back. A recording of a sustained flute tone will probably not imply any diffuse noise band, but such tones are unusual. Normally $33 \frac{1}{3} \mathrm{rpm}$ is used for scratching, but also $45 \mathrm{rpm}$. These numbers can be adjusted a certain percentage in both directions depending on the product: a Technics manages $8 \%$ tempo increase and decrease. $8 \%$ creates a span of almost a musical major sixth (from $302 / 3$ to $483 / 5 \mathrm{rpm}$, a factor of 1.58). Perceived pitch is most influenced by the playback speed on the sample caused by the hand movements. There are no musical restrictions (i.e. tonally or melodically) to which audible frequencies can be used, and no concerns about preserving the original pitch of the source recording. For a $500 \mathrm{~Hz}$ tone to reach $15 \mathrm{kHz}$, however, playback at 30 times the original speed, or $1000 \mathrm{rpm}$, is required, which is impossible for a human DJ to accomplish. Different source recordings cover the whole frequency range, and may even exceed the pick-up's range.

\subsection{Hand motion}

\section{PLEASE INSERT FIGURE 05 HERE!}

Each DJ has a personal approach to moving the record, even though the aim is a welldefined technique. There seems to be an agreement among performers on how it should sound, but not so much on how it is accomplished. Since the record has a large area for positioning hands and fingers, and the turntable can be rotated and angled as preferred, the movements can be organized with great variety (Fig. 5). 


\subsection{Without crossfader}

The most fundamental technique, also recognized as the first scratch, is done by pushing the record forward and backward, and without using the crossfader. When done in a steady rhythmical pattern of for example sixteenth-notes it is called baby-scratch. Movement types number (b) and (e) and the combination of (e) and (c) from Fig. 2 are most frequent in baby-scratching. How fast the turntablist turns the record direction influences both attacks and decays. A long slowdown or start gives a noticeable glissando-like sound. In addition, the frequency-drop will make the listener experience amplitude decrease, thoroughly explained by Moore (1997). This can also be extrapolated from equal loudness contours and FletcherMunson diagrams (Fletcher \& Munson, 1933; Hall, 1980).

\section{PLEASE INSERT FIGURE 06 HERE!}

Another fundamental technique is the tear-scratch that divides one stroke, usually the backstroke, in two. The division is kind of a halt before returning the sample to the starting point. It is not necessary that the record stops entirely in the backstroke, but the fall in frequency and amplitude will give an impression of a new tone attack. Figure 6 shows how the simple division inflicts the sound.

Two techniques take advantage of a trembling motion on the record. Tensing the muscles on one arm to perform a spasm-like movement is called a scribble-scratch. Dragging the record with one hand while holding one finger of the other hand lightly against the direction, letting it bounce on the record, make a stuttering sound called hydroplane-scratch.

\section{PLEASE INSERT FIGURE 07 HERE!}

Both hydroplane- and scribble-scratches produce continuous breaks in the sound. On a spectrogram of a hydroplane-scratch, Fig. 7, it is possible from the tops and valleys around 1 $\mathrm{kHz}$ to trace how the finger bounces on the vinyl. The diminutive slowdowns at a frequent rate, here about 30 per second, produce a humming sound. The broad maximum makes jumps of about $1 \mathrm{kHz}$ in these slowdowns.

\subsection{With crossfader}

The volume controls can cut a sound in or out at will, which also triggered the experiments of Pierre Schaeffer in the fifties (Palombini, 1993). He discovered that when removing the attack of a recorded bell sound, the characteristics could change to that of a 
church organ, for instance. Normally the turntablists let the crossfader abruptly cut the sound, in this way cutting the transition. The sound can easily be turned on and off several times per second, making the scratches sound very fast. This is probably one reason why scratching sounds so recognizable and inimitable. Some techniques are just baby-scratching with varying treatment of the crossfader. Others use longer strokes with quick crossfader cutting.

\section{PLEASE INSERT FIGURE 08 HERE!}

Forwards and backwards, chops and stabs all hide one of the two sounds in a babyscratch, either the forward push or the backward pull. In chirps only two snippets of sounds are heard from a very fast baby-scratch. On every movement forward, the fader closes fast after the start, and backwards only the last bit of the sound is cut in. At these points of the scratch, the vinyl speed is high and so the broad maximum of the noise band is high, $2 \mathrm{kHz}$ in Fig. 8. The drawn line, adapted from the baby-scratch spectrogram in Fig. 3(b), shows the probable broad maximum curve of the forward and backward movement with $0.1 \mathrm{~s}$ silenced, hiding the turn of record direction.

The most debated technique is the flare-scratch, with all its variations. Flaring means cutting out sound during the stroke, but discussions among the performers concern how many times and how regular these cuts should occur. In a relatively slow forward movement that starts with the sound on, the sound is quickly clicked off and back on by bouncing the crossfader between thumb and index finger. Various flares are given names based on the number of such clicks. A 2-click flare is one stroke with two clicks, or sound-gaps, producing a total of three onsets. An orbit or orbit flare is the same type of scratch on both forward and backward strokes. In a 2-click orbit flare there will be a total of six onsets; three on the forward stroke, one when the record changes direction and two on the backward stroke. The flaring-technique generates many other techniques.

\section{PLEASE INSERT FIGURE 09 HERE!}

Twiddle and crab further take advantage of the possibility to bounce the light crossfader between thumb and other fingers, making a rapid series of clicks. The superficial similarity with the tremolo in flamenco-guitar is evident. Figure 9 comes from a twiddle, where the index and middle fingers on the left hand thrust the crossfader on the thumb. The short gaps are easily audible even in a very short scratch.

Because the numerous clicks are done in one single stroke, the frequency of each attack or tone will be quite stable. Roughly speaking, flutter-tongue playing on brass instruments and flutes produces a similar sound (Meyer, 1972).

\section{PLEASE INSERT FIGURE 10 HERE!}


The old technique transformer-scratch is often compared to strobe lights, as the crossfader is pushed on and off fast and rhythmically during relatively long and slow strokes, or even at original playback speed. Figure 10(b) shows a spectrogram of a typical transformerscratch section. Transforming generally attains greater tonal variety than the techniques where the main musical purpose is rapid fader clicks, as for instance in the twiddle-scratch.

\subsection{Relevance in music}

Techniques are seldom played individually for longer periods, but are blended and intertwined for greater expression and musical substance. When hearing, for instance, a twoclick flare-scratch and a twiddle-scratch in succession it might be difficult to distinguish the techniques from each other. That is not the intention either. Turntablists often refer to the different playing styles and scratch solos in terms of flow, and the whole seem to be more important than the components. Mastering one single scratch should be compared to mastering a scale (or rather being able to take advantage of in-scale-notes) in tonal improvisation. Without the sufficient skills, complicated patterns will not sound good, at least to appreciating and accustomed ears. Aspiring DJs will as other musicians have to devote hours to training every day to get the timing right.

\section{Scratch-equipment based on digital technology}

Expensive equipment and hard-to-learn playing techniques are motivations for developers of turntable-imitating hardware and software. Several scratch simulators have emerged during the last ten years, but none have proven to be successful among the professionals. This is bound to change, and one of the promising products today is the Pioneer CDJ 1000, developed for CD-scratching. What it really does is loading some seconds of music into its memory. This memory can easily be accessed via a so-called "scratch pad", and the vinyl record simulation is good enough for more than just the basic scratching. Numark (Axis 9), American DJ (Velocity) and Denon (DN-S5000) make other "scratchable" CDplayers. MP3 and MiniDisc players can be based on the same technology of buffering sound, for example in American DJ ProMix MP3 and Soundgraph D-Vinyl 2020. FinalScratch and $D$-Vinyl represents a new concept where a turntable is used for controlling recorded sound in different formats (for wave and MP3 on Linux) with the help of a coded record.

The scratch-simulating software without a physical controller is interesting mostly because of the low expenses. TerminatorX for Linux and OTS JukeDJ for PC are already introduced, but they have yet to prove to be useful for more than entertainment. People seem to like the idea of scratching in software, and many games profit from this, both in advanced arcade games (Konami's Beatmania, even adapted for Sony Playstation) and simple Flashwave and Shockwave applications (ScratchIt Old School and Turntables New School, ScratchDeLux, DJ FU Wax Attack). 


\section{Reflections}

It is not obvious to see whether models of scratching will hold a comparison to vinyl technology. All simulators have in common its digital approach, which is quite natural, but there are benefits and catches with vinyl that is either overlooked or even sidestepped. One specific example of a vinyl-typical feature is the deterioration of the vinyl; a few minutes of dragging the needle continually over the same spot on the record has devastating consequences for the sound quality, and based on experiences from DJs, the needle even responds differently to movement over that spot. CD players will not wear out grooves the same way a record player does, and this might take the edge off a sound the same way a producer in a recording studio can polish a rough performance to the nearly unbearable.

To simulate every aspect of the turntable, the vinyl, the needle and the more remote aspects like wearing, will probably turn out to be the only suitable option for making an acceptable replacement for today's instrument set-up. An approach built on physics-based modelling technique seems therefore appropriate and worth to experiment with in the future (Rocchesso, Bresin \& Fernström, in press).

Arguably, the most characteristic quality in scratching is the big range of recognizable and universally agreed-upon playing techniques. Future research can reveal interesting issues regarding these. Also, technology aiming to replace the turntable should take into consideration the role and practises of scratch techniques. The techniques and characteristics of the hand movements associated with different types of scratches will be examined in future investigations. 


\section{Acknowledgements}

I am very grateful to Roberto Bresin and Johan Sundberg for invaluable help and encouragement.

I would like to thank the renowned and skilled DJ 1210 Jazz, Alexander Danielsson, for wonderful scratching, equipment and for being unfailingly helpful. Thanks to Scratchaholics for enlightening and helping me.

This work was supported by the EU IHP Network MOSART (Music Orchestration Systems in Algorithmic Research And Technology, HPRN-CT-2000-00115). 


\section{References}

American DJ (2002). Velocity and ProMix. Available: http://www.americandj.com/.

Byrne, D. (1997). Feelings ${ }^{\circledR}$. CD: 46605. New York: Luaka Bop/Warner Brothers.

Cage, J. (1939). Imaginary Landscape No 1. New York: Edition Peters.

Cutler, C. (1994). Plunderphonia. MusicWorks 60, 6-20. Toronto: MusicWorks. Available online: http://www.l-m-c.org.uk/texts/plunder.html.

Denon (2002). DN-S5000. Available: http://denon.jp/europe/pdf/dns5000.pdf.

Doublemind.com (1999). SckratchIt old school (Flashwave application). Available:

http://www.turntables.de/.

Ecler. Available: http://www.eclerdjdivision.com/.

Fab Five Freddie (1982). Change the beat. 12” LP: CEL 156. New York: Celluloid Records.

FinalScratch (2001). Available: http://www.finalscratch.com/.

Fletcher, H. \& Munson, W.A. (1933). Loudness, its definition, measurement and calculation. Journal of Acoustical Society Of America, 5, 82-108.

Godlovitch, S. (1998). Musical Performance: A philosophical study (pp. 52-78). London: Routledge.

Griffiths, P. (1995). Modern music and after (pp. 17-19). Oxford: Oxford University Press.

Hall, D.E. (1980). Musical Acoustics (pp. 114-119). Belmont, CA: Wadsworth Publishing Company.

Hancock, H. (1983). Future Shock. CD, reissue 2000: 65962. New York: Columbia/Legacy.

Hansen, K.F. (1999). Turntablisme - His Master's Voice: The Art of the Record Player. Trondheim: NTNU.

Hansen, K.F. (2000). Turntable Music. In: Jonsson, L., Oversand, K. \& Breivik, M. (Eds.) Musikklidenskapelig Årbok 2000 (pp. 145-160). Trondheim: NTNU. Available on-line: http://www.speech.kth.se/ hansen/turntablemusic.html.

Hitech Development. Soundswell Signal Workstation. Available: http://www.hitech.se/development/products/soundswell.htm.

Khazam, R. (1997). Electroacoustic alchemist. The Wire Magazine, 160, 36-40.

Konami (2002). Beatmania. Available: http://www.konami.co.jp/am/bm/.

Meyer, J. (1972). Akustik und musikalische Aufführungspraxis. Frankfurt a/M.: Verlag das Musikinstrument. 
Moore, B.C.J. (1997). An introduction to the Psychology Of Hearing. London: Academic Press.

Mr Bungle (1991). Mr Bungle. CD: 2-26640. New York: Warner Brothers.

Numark (2002). Axis 9. Available: http://www.numark.com/.

Ortofon. Available: http://www.ortofon.com/.

OTSJuke (2002). OTSJuke DJ. Available: http://www.otsjuke.com/support/scratching/.

Palombini, C. (1993). Pierre Schaeffer - From Research into Noises to Experimental Music. Computer Music Journal, 17(3), 14-19. Cambridge, MA: MIT Press.

Phattunes.net (2000). Turntables new school. Available: http://www.turntables.de.

Pioneer (2001). Pioneer CDJ 1000. Available:

http://www.pioneerprodj.com/products/cdj1000/cdj1000.mv.

Portishead (1994). Dummy. CD: 828 553. London: Go! Discs.

Rane (2001). TTM 56. Available: http://www.rane.com/djcat.html\#mixersttm56.html.

Rocchesso, D., Bresin, R. \& Fernström, M. (in press). Sounding Objects. IEEE Multimedia Magazine.

Schaeffer, P. (1948). Etude aux Chemins de Fer.

ScratchDJ (2002). American turntablism site with forum. Available:

http://www.scratchdj.com/.

Shockwave (1999). DJ Fu: Wax Attack. Available:

http://www.shockwave.com/sw/content/djfu01/.

Shure. M44-7 cartridge. Available: http://www.needlz.com/m44-7.asp. V15 VxMR cartridge. Available: http://www.shure.com/v15vxmr.html.

Sillon-delux (1999). SkratchDelux. Available: http://www.sillon-delux.com/ (extras).

Sjölander, K. \& Beskow, J. Wavesurfer - An Open Source Speech Tool. Available:

http://www.speech.kth.se/wavesurfer/.

Smith, R. (1999). Online 1200 Technics SL1200 Mk2 specifications. Obsolete, but available through web archive:

http://web.archive.org/web/20011020001924/http://www.turntablism.com/online1200/.

Soundgraph (2002). DJ Pad-Vinyl 2020. Available: http://www.d-vinyl.dj/.

Stanton. 890SA cartridge. Available: http://www.stantonmagnetics.com/stingray/index2.asp.

Technics. SL-1200 and 1210 Mk2. Available: http://www.panasoniceurope.com/technics/products/product_detail.asp?range $=\mathrm{dj}$. 
TerminatorX (2002). Available: http://www.terminatorx.cx/.

Vestax (2002). Samurai series mixers. Available:

http://www.vestax.com/products/samurai.html.uk/.

Waits, T. (1999). Mule Variations. CD: 86547. Los Angeles, CA: Anti/Epitaph.

Zorn, J. (1982). Locus Solus. CD reissue, 1995: 7303. New York: Tzadik. 


\section{Figure legends}

Figure 01. Rane TTM56 scratch mixer (a). Close-up on crossfader and volume controls (b).

Figure 02 . Eight ways to start and end a forward and backward movement over a sample's borders.

Figure 03. Waveform (a) and spectrogram (b) of sounds produced by common simple forward and backward hand movements.

Figure 04. Waveform (a) and spectrogram (b) of two simple forward and backward movements.

Figure 05. Different hand positions taken from a performance by DJ 1210 Jazz.

Figure 06. Waveform (a) and spectrogram (b) of tear-scratch.

Figure 07. Spectrogram of hydroplane-scratch.

Figure 08. Spectrogram of chirp-scratch.

Figure 09. Waveform (a) and spectrogram (b) of twiddle scratch.

Figure 10. Waveform (a) and spectrogram (b) of transformer-scratch. 


\section{Keywords}

Scratching, turntablism, DJ, mixing, playing techniques.

\section{About the author}

Kjetil Falkenberg Hansen has been a researcher at the Speech, Music and Hearing department of the Royal Institute of Technology in Stockholm since 2001. His studies of scratching started at the Department of Musicology at the Norwegian University of Science and Technology in Trondheim in 1998. From looking at musicological issues and possibilities for musical analysis, the focus has gradually moved towards organological and lately acoustical approaches. Hansen has published one book (in Norwegian) and two articles regarding scratching and turntablism. 